\title{
C4 article: Implications of COVID-19 in transplantation
}

\section{Contributors to the $\mathrm{C} 4$ article}

\section{Correspondence}

Deepali Kumar

Email: deepali.kumar@uhn.ca
A novel coronavirus has had global impact on individual health and health care delivery. In this C4 article, contributors discuss various aspects of transplantation including donor and recipient screening, management of infected patients, and prevention of coronavirus disease (COVID). Donor screening with SARS-CoV-2 nucleic acid testing (NAT) close to the time of procurement is recommended. Many programs are also screening all potential recipients at the time of admission. The management of COVID has evolved with remdesivir emerging as a new potential option for transplant recipients. Dexamethasone has also shown promise and convalescent plasma is under study. Prevention strategies for transplant candidates and recipients are paramount. Pediatric-specific issues are also discussed. Strategies for the psychological well-being of patients and providers are also imperative, in addition to future research priorities for transplantation.

KEYWORDS

clinical research/practice, infection and infectious agents, infection and infectious agents viral, infectious disease, organ transplantation in general

\section{1 | INTRODUCTION}

SARS-CoV-2, a novel coronavirus, originated in China in late 2019 and has since caused an unprecedented pandemic with COVID19 impacting almost all regions globally. Mortality is estimated to be $1 \%-3 \%$ and the predominant risk factor for mortality is age $>60$ years along with comorbid illnesses such as hypertension. Interestingly, children are less impacted although there are recent reports of a Kawasaki-like inflammatory syndrome that may be linked to COVID-19. Although the majority of severe disease involves the respiratory tract, other complications such as neurologic disease (confusion, cognitive difficulties, early strokes) as well as a hypercoagulable state can occur. Organ donation and transplantation have been greatly impacted by the pandemic. Donation rates significantly fell during the pandemic peaks although there was some geographic variability in this. Living donor transplantation was halted in many areas due to anticipated lack of hospital capacity and the concern for nosocomial transmission of virus. Significant concern was generated

See Appendix 1 for the full list of editors and contributors. that high rates of severe COVID-19 disease would be seen in immunosuppressed transplant recipients. Indeed, transplant recipients appear to have a greater risk of mortality than the general population, although the exact increase in risk is difficult to ascertain as this has varied among studies and with time. Several case reports and case series of transplant recipients with COVID-19 have now been published and mortality ranges $18 \%-30 \%$, although these studies are primarily reflective of a hospitalized population. ${ }^{1-3}$ The potential bias in a more severely affected population needs to be taken into account during the interpretation of morbidity and mortality data. Serosurveys may shed more light in terms of how many transplant patients may have had milder disease courses. Notably, this is a rapidly changing situation, thus we are focusing on the current state of the disease.

This is the third in a series of C4 (defined as current, controversial, collaborative, and crowdsourced) articles that was first published by the American Journal of Transplantation in 2018. Given the uncertainties of the COVID-19 pandemic with regards to management of transplant patients and programs, we initiated a C4 
article in order to better outline the issues. Editors chose seven topics that were relevant to COVID-19 in transplantation including the management of the infected transplant patient, donor screening, preventative measures in transplantation, transplant program management as well as how to protect the transplant team. We also specifically highlight pediatric issues as well as psychological and ethical considerations. The general epidemiology, virology, or immune responses of COVID-19 are discussed only as they are relevant to transplantation.

\section{2 | METHODS}

The editorial team (denoted by ${ }^{*}$ in Appendix A) organized the article into relevant sections, highlighted some points to start the discussion, and invited several experts and members of the transplant community to contribute to the article via a public link to the Dropbox article (San Francisco, CA). Contributors were verified through Google docs and no contributor was excluded. The link was posted on the American Journal of Transplantation website and promoted by word of mouth. The article was open for 4 weeks from April 15, 2020 to May 15, 2020 for contributions. Similar to previous $\mathrm{C} 4 \mathrm{~s}$, this article has 61 unique contributors or editors with 103 views by week 2 and an additional 73 views by week 4 . After the second and fourth week, the versions were archived. Following this, the editors revised their sections and previous versions were available to view as Dropbox files (Week 2 archive: https://paper.dropbox.com/doc/COVID-19-IN-TRANSPLANT ATION--A7vt0KqLGeSUwuelOyxINXIwAg-OT71bBK2J6GXhwS Zxh6KJ and Week 4 archive: https://paper.dropbox.com/doc/ COVID-19-IN-TRANSPLANTATION--A7suzteBq3PhrMLqxejK JnaRAg-r4nOoA7TYIUOiRilDAZnf). The editors were responsible for summarizing their sections and ensured that similar contributions were combined and the appropriate references were added. Editors ensured that contributor thoughts were placed in the appropriate section to minimize duplication. This $\mathrm{C} 4$ differs from previous $\mathrm{C} 4$ articles since it tackles a topic where data continues to rapidly emerge. Therefore, some salient transplant and nontransplant studies published after the closure of contributions as well as those based on peer-reviewer comments were highlighted by the $\mathrm{C} 4$ editors. However, the message provided by the contributors was retained.

\section{3 | DISCUSSION}

\section{1 | Diagnostics for COVID}

While some clinical symptoms are more strongly associated with COVID-19, such as loss of smell or taste, most are not pathognomonic of the infection. As such, diagnostics are needed to confirm infection with SARS-CoV-2. Currently diagnostics are focused on clinical assessment, detection of virus by nucleic acid testing (NAT), and detection of antibodies to SARS-CoV-2. Limitations of reagents, testing capacity, test components, especially swabs, and testing locations still exist.

\subsection{1 | Molecular diagnostics}

Real-time polymerase chain reaction (RT-PCR), using a laboratory developed test (LDT) or a commercial assay, is the main diagnostic approach at most centers. Assays utilize different viral targets (RdRp, E gene, spike, Open Reading Frame [ORF] 1a, and nucleocapsid [N]). ${ }^{4}$

The underlying kinetics of viral infections are key to understanding PCR test performance. Viral replication begins 24-48 hours prior to symptom onset and peaks at days 3-5 after symptom onset. ${ }^{5,6}$ Patients with more severe infections typically have higher viral loads in all locations and shed virus longer (21 vs. 14 days). ${ }^{7,8}$ Higher viral loads are noted with increasing age. While viral shedding is prolonged for many patients, for those with mild disease, culturable virus is generally no longer detected when the viral load drops below $10^{6}$ copies or $\mathrm{Ct}$ (cycle threshold) value $>34$ which generally occurs around day 8 after symptom onset. ${ }^{9,10}$ Virus has been detected outside the respiratory tract, including the blood and stool, but these sites are not typically sampled for diagnostic purposes. ${ }^{11}$

False-negative PCR testing from upper airway samples is more common very early and late after infection. Likewise, patients with pneumonia who may have detection of virus from lower but not upper respiratory tract samples have been described. False-negative PCR testing may occur with worsening clinical status later in the disease course. ${ }^{12}$ As discussed below, serologic testing for SARS-CoV-2, may be useful in this setting. Across studies, samples from the lower respiratory tract have consistently had both higher viral loads and a higher percent positivity rate versus nasal samples (93\% vs. $63 \%)^{13,14}$ Several studies have demonstrated saliva to yield excellent sensitivity and slightly higher viral loads than nasal swab with significant ease in collection. ${ }^{7,15}$

Several studies have demonstrated the ability to detect virus from asymptomatic and presymptomatic patients. Virus in these patients can frequently be cultured suggesting presence of transmissible virus. ${ }^{16,17}$

In the United States, all current SARS-CoV-2 assays are being used under Emergency Use Authorization (EUA, https://www. fda.gov/medical-devices/emergency-situations-medical-devices/ emergency-use-authorizations). Without a gold standard of diagnosis, it is difficult to define these test characteristics and the performance of the assays approved under the EUA has not been widely studied. The few studies that have been completed suggested excellent sensitivity and specificity with agreement across most assays; most have noted slightly lower sensitivity with the Abbott ID Now system. ${ }^{18-21}$ 


\subsection{2 | Radiological assessment}

Several studies have suggested that CT scans of chest are more sensitive than upper respiratory PCR testing early in the disease course. ${ }^{22,23}$ Findings are typically nonspecific and testing poses risk of exposure to radiology staff, so current guidelines generally do not recommend imaging for the diagnosis of COVID-19 (https:// www.acr.org/Advocacy-and-Economics/ACR-Position-Statements/ Recommendations-for-Chest-Radiography-and-CT-for-SuspectedCOVID19-Infection). However, in cases of high suspicion for COVID19 lower respiratory tract disease and repeated PCR negativity, a CT chest can be done although radiologic findings of COVID-19 are not specific.

\subsection{3 | Serologic testing}

Measuring antibody responses to SARS-CoV-2 may be useful for clinical, epidemiologic, therapeutic, and prevention efforts. In particular, serologic testing may have a role in (1) detection of PCRnegative cases, especially for patients who present late with viral loads below the detection limit of RT-PCR assays; (2) identification of convalescent plasma donors if quantitative assays are used; (3) contact tracing after a suspected exposure; (4) epidemiologic studies of disease prevalence in the community; and (5) verification of vaccine efficacy. However, serologic testing is also fraught with pitfalls due to technical and analytical heterogeneity, especially when tests are not rigorously validated (leading to false positives and false negatives) and when testing is applied to a mass scale in low prevalence settings (leading to false positives). The benefits and approaches of serology have been reviewed extensively elsewhere. $^{4}$

IgM antibodies begin to develop 3-7 days after symptom onset with IgG developing on symptom days 11-14; most are positive by 3 weeks after symptom onset. ${ }^{24}$ Titers typically decline after 2 months, as they do with many infections, but the duration of protection is not well studied to date. Furthermore, assays are just beginning to be validated and current tests have a wide range of sensitivity and specificity. Few of the available tests confirm the detection of neutralizing antibodies.

\section{2 | Management of the COVID+ transplant recipient}

Patients infected with SARS-CoV-2 can have dramatically different courses of illness. Risk factors for severe disease include comorbidities such as obesity, diabetes, hypertension, renal disease, cardiovascular disease, chronic respiratory disease, and cancer. Risk factors for mortality include older age, higher Sequential Organ Failure Assessment score, and d-dimer $>1 \mathrm{mcg} / \mathrm{ml}$ on admission. ${ }^{25}$ Some reports suggest that transplant recipients are at greater risk of complications of COVID-19 owing to immunosuppression whereas others infer that the immunosuppression has a limited impact and it is the comorbidities that drive the risk. ${ }^{26,27}$

Optimal strategies for antiviral and immune-based therapies have not been established; all drug therapies remain investigational. Over 1200 clinical trials worldwide and over 250 in the United States are recruiting or have been completed (covid-trials.org), evaluating over 30 agents that may have efficacy against SARS-CoV-2. ${ }^{28}$ Treatment guidelines for COVID-19 are published by the National Institutes of Health, ${ }^{29}$ and management varies by severity of illness (Table 1 ).

Asymptomatic and mild infections can be managed at home. Priorities include close monitoring for clinical deterioration as well as isolation in order to prevent transmission to others. Acetaminophen can help manage fever and myalgia. Nonsteroidal anti-inflammatory drugs are not known to be problematic in patients with COVID-19, ${ }^{30}$ although they are often avoided to prevent nephrotoxicity in transplant recipients taking concomitant calcineurin inhibitors. Despite initial reports, renin-angiotensin-aldosterone system inhibitors should be continued in patients in stable condition. ${ }^{31,32}$

Moderate and severe disease requires hospital admission for supportive care. At a minimum, routine monitoring should assess for fever, myalgia, Gl symptoms, respiratory status, renal dysfunction, myelosuppression, thrombosis, and psychiatric assessment. Hospitalized adults should receive venous thromboembolism prophylaxis. Empiric broad spectrum antibiotics should be given if bacterial pneumonia or sepsis is suspected, with daily reevaluation and de-escalation or discontinuation as soon as able. As per the RECOVERY trial, patients who require supplemental oxygen or mechanical ventilation may derive a mortality benefit from dexamethasone. ${ }^{33,34}$ This benefit appears limited to patients who are more

TAB LE 1 COVID-19 categories of illness (assumes SARS-CoV-2 PCR is positive)

\begin{tabular}{ll}
\hline $\begin{array}{l}\text { Asymptomatic or } \\
\text { presymptomatic infection }\end{array}$ & $\begin{array}{c}\text { Individuals who test positive for SARS-CoV-2 by virologic testing using a molecular diagnostic or antigen test, } \\
\text { but have no symptoms } \\
\text { Mild illness }\end{array}$ \\
$\begin{array}{l}\text { Individuals who have any of various signs and symptoms (eg, fever, cough, sore throat, malaise, headache, muscle } \\
\text { pain) without shortness of breath, dyspnea, or abnormal chest imaging }\end{array}$ \\
\hline Individuals who have evidence of lower respiratory disease by clinical assessment or imaging and a saturation of \\
oxygen $\left(\mathrm{SpO}_{2}\right)>94 \%$ on room air at sea level \\
Severe illness \\
$\begin{array}{l}\text { Individuals who have respiratory frequency }>30 \text { breaths per minute, } \mathrm{SpO}_{2} \leq 94 \% \text { on room air at sea level, ratio of } \\
\text { arterial partial pressure of oxygen to fraction of inspired oxygen }\left(\mathrm{PaO}_{2} / \mathrm{FiO}_{2}\right)<300 \text {, or lung infiltrates }>50 \%\end{array}$ \\
\hline Critical illness & Individuals who have respiratory failure, septic shock, and/or multiple organ dysfunction
\end{tabular}

Note: National Institutes of Health. COVID-19 Treatment Guidelines Panel. Coronavirus Disease 2019 (COVID-19) Treatment Guidelines. Available at https://www.covid19treatmentguidelines.nih.gov/. Accessed 8/02/2020. 
than 7 days from symptom onset. In the setting of a dexamethasone drug shortage, equivalent doses of prednisone, methylprednisolone, or hydrocortisone should be considered. ${ }^{29}$

Therapies used in the treatment of COVID-19 are the same in transplant recipients as in non-transplant patients (Table 2). Several potential antiviral therapies used early in the pandemic including hydroxychloroquine $e^{35-37}$ and lopinavir/ritonavir have been found ineffective and should not be used to prevent or treat infection in transplant patients. ${ }^{38}$ The most promising antiviral at this time is remdesivir, which has been fully or conditionally approved by health authorities around the world based on clinical trials. ${ }^{39-41}$ It is currently available in the United States through an FDA Emergency Use Authorization for select patients with severe COVID-19. ${ }^{42}$ Note that the data on anti-viral therapies are primarily derived from a non-transplant population. The FDA has also issued guidance on the use of convalescent plasma, ${ }^{43}$ rendering it classified and regulated as an investigational product. For adults, COVID-19 convalescent plasma is available as a treatment option in the United States through an expanded access program (uscovidplasma.org). Detailed information for health care providers, patients who have recovered from COVID-19 infection and are willing to donate plasma, and for patients who are considering this treatment is available at https://ccpp19.org/. It is unknown if convalescent plasma will be associated with an increased risk of rejection due to off-target effects.

Accumulating evidence suggests that the cytokine storm triggered by SARS-CoV-2 may be responsible for severe lung injury. ${ }^{44}$ Several case series have shown a benefit for IL-6 inhibition with tocilizumab in reducing mortality in ventilated patients or reducing progression to mechanical ventilation in severe disease. ${ }^{45-47}$ In a cohort of 80 kidney transplant patients treated with tocilizumab, there was a decline in inflammatory markers. ${ }^{48}$ However, phase III studies for IL-6 inhibition have not demonstrated clinical efficacy ${ }^{49,50}$; studies of other agents are under way and the tocilizumab arm of the RECOVERY trial is yet to be analyzed..$^{51}$ Nevertheless, the optimal use of these agents may depend on the correct timing of administration in the inflammatory cascade. It is currently unknown whether or not interruption of transplant immunosuppression may exacerbate the inflammatory response to SARS-CoV-2 and have a detrimental effect. There is general agreement that there is no chemoprophylaxis, and no need to modify or stop immunosuppression in asymptomatic or mild disease. Decreasing immunosuppressant medications may be considered according to the severity of illness, but complete withdrawal of immunosuppression has not been recommended. ${ }^{52}$ The optimal way to manage immunosuppression remains unknown. Many experts reduce the antimetabolite first followed by the calcineurin inhibitor. There are no clear target trough levels although these may depend on the organ transplanted as well as time from transplant. More recently, dexamethasone is shown to reduce mortality in hospitalized COVID patients although it is unclear how beneficial this strategy would be in transplant recipients given the ongoing immunosuppression and potential for secondary infections. ${ }^{33}$

\section{3 | Prevention strategies for the transplant recipient}

Prevention methods for COVID-19 are likely familiar to transplant patients, who were already encouraged to avoid unnecessary community and health care exposures through social distancing and infection control, practice enhanced hygiene, and optimize immunosuppression and comorbidities. It is not yet known whether alterations in social distancing measures (eg, ongoing distancing even if restrictions lifted for general population) would be more effective for this population. Universal face masks are now standard in guidelines for infection prevention. This strategy was studied in the hematopoietic stem cell transplant population, where a universal surgical mask policy was implemented for all individuals with direct patient contact; respiratory viral infections decreased from $10.3 \%$ in the premask period to $4.4 \%$ in the mask period $(P<.001){ }^{53}$ Extrapolating this concept to SOT recipients, their caregivers, and contacts is a recommended strategy during the COVID-19 pandemic.

Whether to screen asymptomatic transplant patients remains an area of debate; some programs screen all patients admitted to a transplant ward regardless of symptoms, while others perform targeted screen only for those undergoing transplant or treatment of rejection. Pre-admission telephone screening by symptom checklist can help with triage; persons under investigation for COVID-19 should be cohorted away from the transplant floors, when possible. Ideally, testing of asymptomatic patients and donors should be performed to avoid transmission to transplant recipients and health care workers. Recommendations for universal screening should be based on the local epidemiology, testing capacity of the laboratory, and access to reliable performing platforms.

Other preventative measures include optimizing comorbidities such as hypertension and diabetes. Patients can be encouraged to monitor blood pressure at home, which has been shown to better correlate with 24-hour ambulatory blood pressure monitoring than office blood pressure in kidney transplant recipients ${ }^{54}$ and overall better blood pressure control. ${ }^{55,56}$ Similarly, optimizing diabetes control through more intensive home monitoring, data collection, and telemedicine is encouraged. Social distancing has resulted in less exercise for many, augmenting these comorbidities; safe methods to exercise and walking should be encouraged. Optimizing patients' self-care at home for common medical comorbidities may enhance both current and future effective medical care. The role of pre-emptive changes in immunosuppression, such as avoiding induction immunosuppression to prevent severe COVID-19 is unknown. For example, in kidney transplantation, literature suggests basiliximab is similar to anti-thymocyte globulin for induction therapy in non-sensitized patients or sensitized patients without donor-specific antibodies. ${ }^{57,58}$ Some programs have enhanced infection control in their belatacept infusion centers ${ }^{59}$ or increased use of home infusions, while others have switched belatacept to non-infusion immunosuppression. There may be risk of transmission of virus associated with blood product transfusions, ${ }^{60}$ suggesting we should avoid unnecessary transfusions until we have more testing of blood products and safety data. 


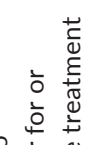

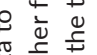

范

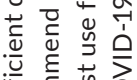

离
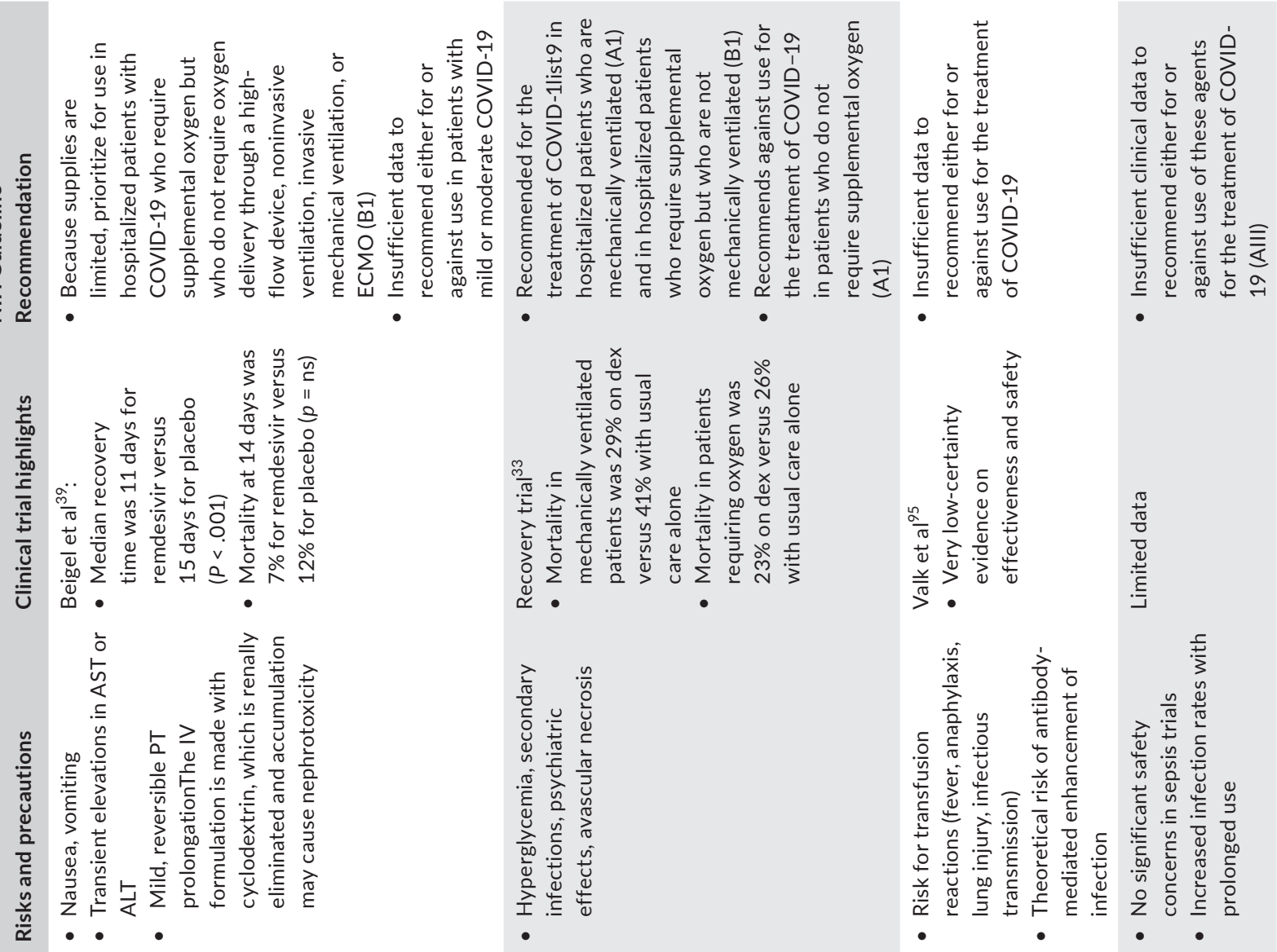

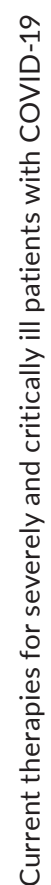

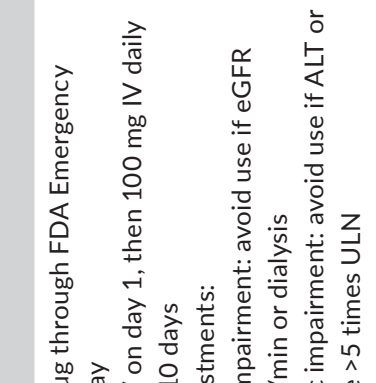

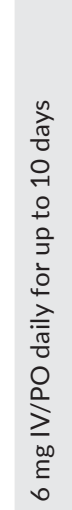

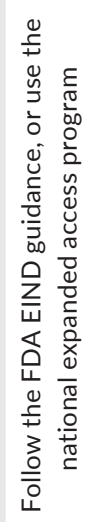

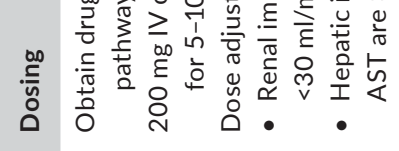
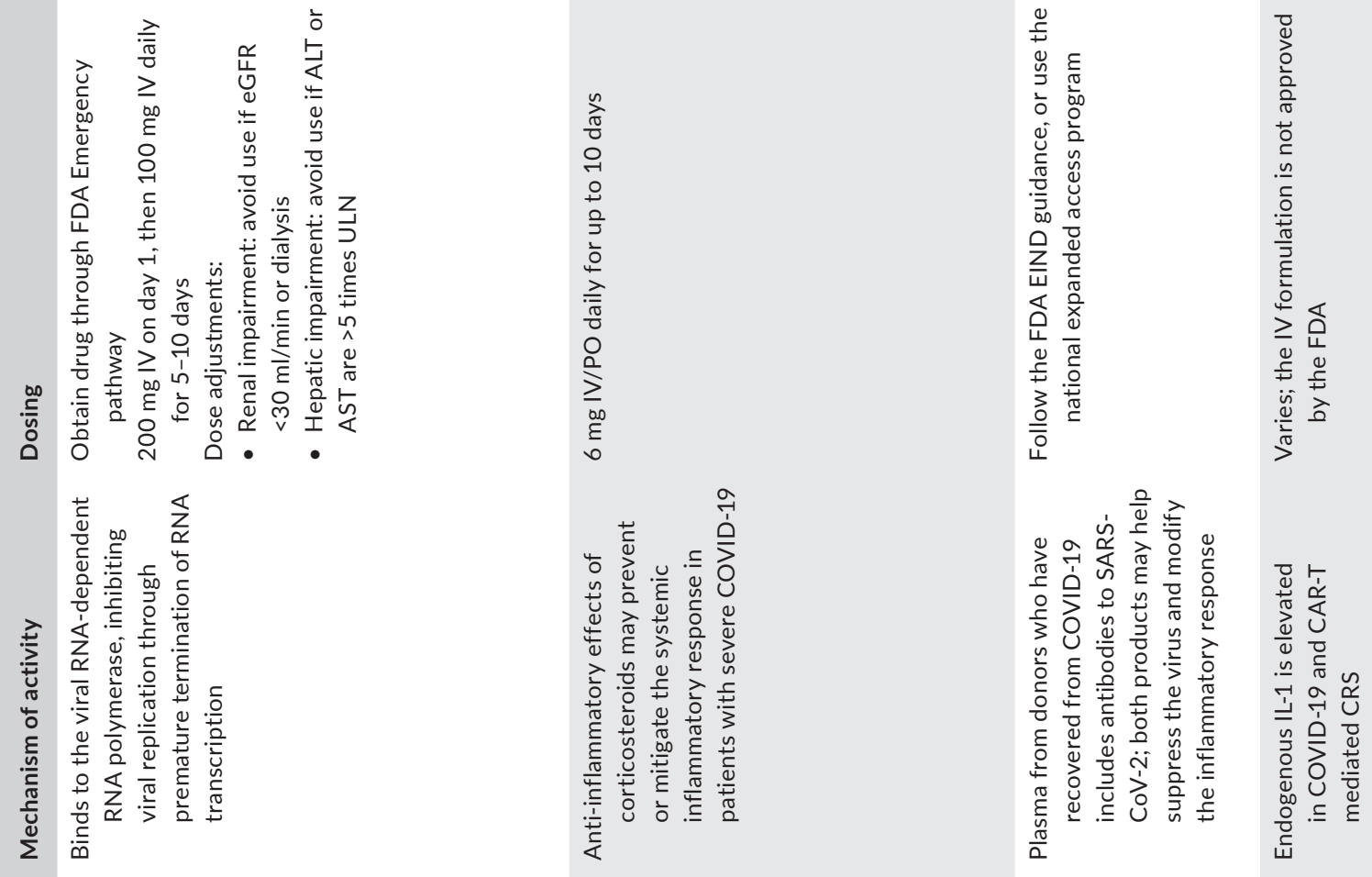

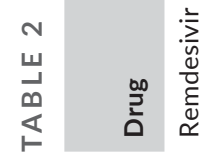

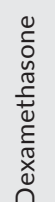

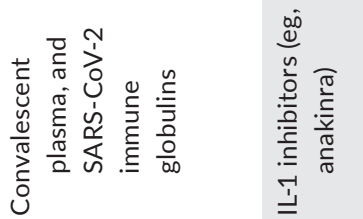




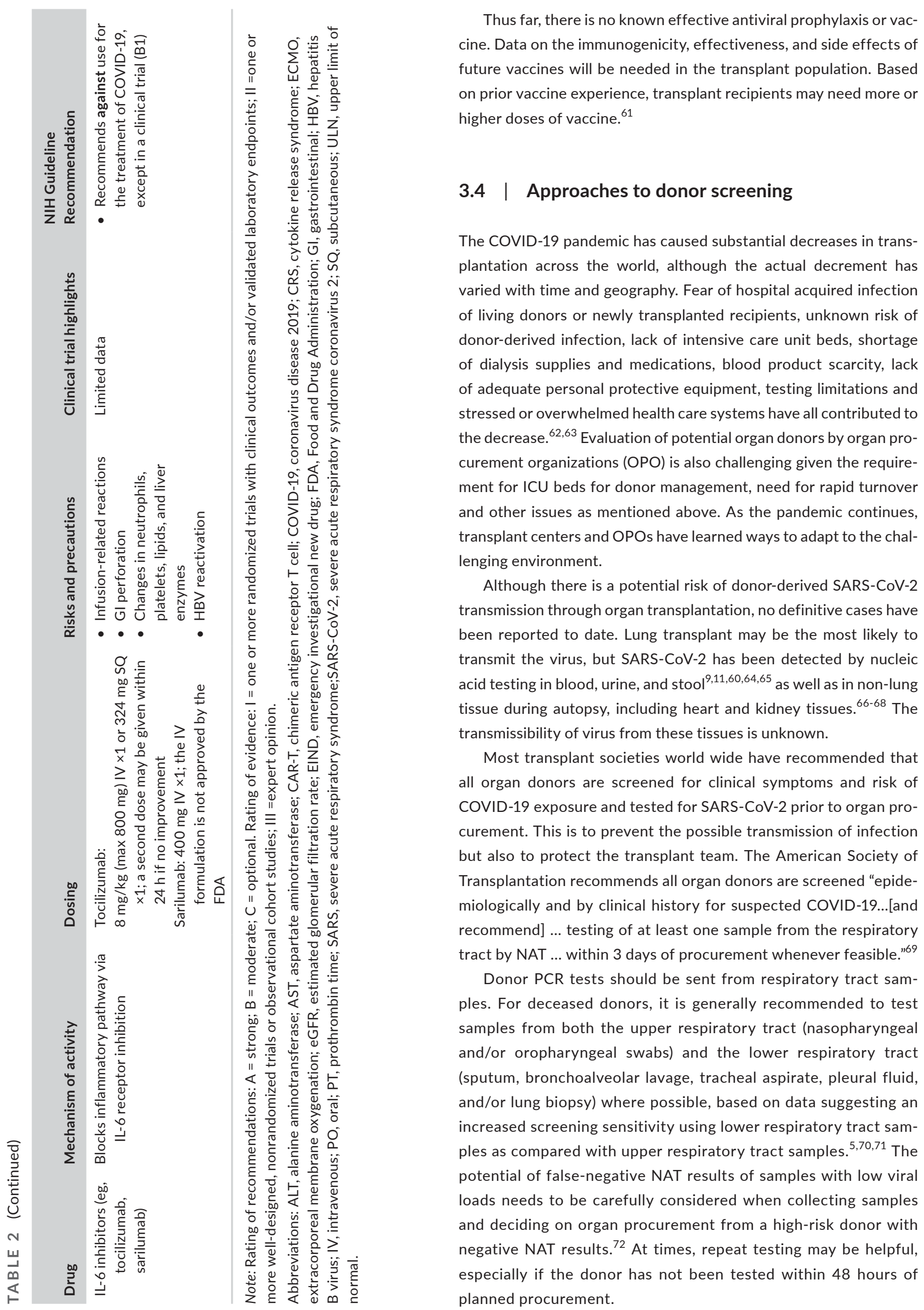


For living donors, screening for COVID-19 infection should also be performed, at a minimum with a clinical screen and with NAT/PCR on a single upper respiratory tract sample; the timing of this depends on the individual donor. If testing is negative, the living donor should be asked to socially distance as much as able and wear a mask when around others until the transplant occurs, especially within 14 days of the planned surgery. Ideally, a repeat clinical screening and PCR test should be performed within 48 hours of donation. ${ }^{69}$

The optimal deferral period is still not known for living donors who test positive for SARS-CoV-2 infection or for deceased donors who have recovered from COVID-19. Based on the average duration of PCR positivity (approximately 20 days), ${ }^{25}$ the American Society of Transplantation (AST) suggests waiting at least 28 days from resolution of symptoms (for living donors) before organ donation can be considered safe. AST recommends declining organs from donors with active COVID-19 infection, SARS-CoV-2 detected on testing as part of the donor hospital or OPO evaluation or who are less than 28 days from resolution of clinical symptoms of a past COVID-19 infection. ${ }^{69}$ This is always with the caveat of balancing the risk of deferring transplantation for a specific recipient.

The best use of serology assays, mainly used for the detection of past infection, has not been established for organ donor screening. It is unlikely that serology for SARS-CoV-2 will be useful to determine donor suitability since it is similar to other viruses that cause acute infections and do not establish latency. Nevertheless, once the performance characteristics of the serology assays are better established, the role of donor serology will become clear.

Given the evolving nature of the pandemic and a need for more data upon which to base permanent policy decisions, there is currently no OPTN policy requiring donor testing, but data are being collected (https://optn.transplant.hrsa.gov/covid-19/). The OPTN has put together an Emergency Policy Package to provide additional flexibility during the COVID-19 crisis ("COVID-19 Emergency Policy Package" [https://optn.transplant.hrsa.gov/media/3716/covid -19_emergency_policypackage_and_minibrief.pdf]). The issues addressed include modification of kidney waiting time, data submission requirements, timely collection of data, and reporting requirements after living donation of kidney or liver.

\section{5 | Considerations of inpatient and outpatient transplant activity}

\subsection{1 | Reductions in new transplant activity}

Transplant activity during the COVID-19 pandemic has been significantly curtailed. ${ }^{73}$ For example, the majority of US transplant programs $(71.8 \%$ on a national survey of transplant centers conducted March 24-31, 2020) completely suspended their living donor kidney transplant programs and most placed modifications and restrictions on deceased donor kidney transplantation ( $>80 \%$ of responding programs).$^{74}$ The reasons for this are multifactorial and include (1) issues related to hospital infrastructure and resources to allow treatment of COVID patients, (2) avoidance of iatrogenic immunosuppression during a time where community or hospital exposure in the transplant recipient is a possibility, (3) concerns regarding living donor safety, (4) concerns related to the potential for COVID transmission via the organ, and (5) an an overall decrease in deceased donation. However, in most situations, transplant activity should not be considered "elective" (https://www.cms.gov/ -March 18, 2020). A possible phased approach to transplant activity reduction was outlined in Kumar et al. ${ }^{62}$

\subsection{2 | Reductions and changes to outpatient activity}

Most programs modified outpatient transplant clinics early in the pandemic as hospitals prepared for increasing numbers of COVID patients. Deferral of routine long-term follow-up visits or a change to virtual platform (telehealth or telephone) is a relatively simple strategy to avoid in-person hospital ambulatory visits. During the COVID pandemic, many jurisdictions have facilitated virtual care platforms and specifically two-way video technology to improve the virtual experience. The expansion of reimbursement options for telehealth services is also of critical importance in ensuring the success and sustainability of virtual models of care. In addition, virtual platforms are useful for many aspects of transplant evaluation, waitlist candidate follow-up and early posttransplant followup care. However, as the pandemic subsides, transplant programs will face a back-log of clinic patients. Programs may need to create additional clinics and continue to leverage the potential of telemedicine to get caught up with the number of patients awaiting to be seen.

\subsection{3 | Approach to phasing up transplant activity}

The decision of when and how to transition from a state of low transplant activity toward a return to "normal" activity is challenging. Transplant programs will need to implement nuanced and individualized approaches based on local SARS-CoV-2 activity and health care system burden.

However, a relatively rapid phasing up of transplant activity is important in order to meet the needs of our patients with advanced organ disease, as well as honor the life-saving gifts of donors. Timing of such initiation is likely to look very different across the country and internationally based on the local level of COVID-19 impact. Scheduling living donor transplants that have been postponed or canceled may be more difficult if competing for OR time and resources with other surgical specialties such as cancer and cardiac surgery where many scheduled patients may have faced unacceptable delays.

Conditions that should be met as phase up is contemplated include (1) processes to ensure safety of recovery teams, (2) robust donor screening process, (3) adequate infrastructure and 
resources in the transplant hospital (OR availability, ICU capacity, work-force, PPE), (4) capacity for outpatient posttransplant follow-up, and (5) appropriate recipient consent and communication processes. A possible phase up plan is shown in Table 3 along with conditions that could allow movement from one phase to another. A multi-disciplinary approach including physicians, staff, hospital leadership, public health and epidemiology etc. is necessary in order to individualize the approach that each center takes regarding the timing of resuming transplant activities. In addition, for transplant hospitals that continue to have a high COVID patient burden, "COVID-free" zones for transplant patients (and living donors) are desirable in order to minimize the risk of nosocomial acquisition.

\subsection{Protecting the transplant team}

Health care personnel (HCP) represent $4 \%-19 \%$ of those infected with SARS-CoV-2. ${ }^{75-77} \mathrm{HCP}$ involved in transplantation is at risk of becoming infected with SARS-CoV-2 in the health care setting from other HCP, transplant candidates, recipients, and SOT donors. ${ }^{78}$ Transplant centers must develop and implement effective strategies to mitigate the risk of HCP infection.

In the outpatient setting, non-urgent encounters and procedures could be deferred. Telehealth and telemedicine are now available and may be enhanced by home digital monitoring programs. They could also be used to provide medical care to stable SOT recipients and those with COVID-19 during the isolation period. All SOT candidates, recipients and living donors should wear a facemask during visits to the health care facility and be screened for symptoms compatible with COVID-19 prior to entry. This evaluation should ideally occur prior to the visit. Those screening positive will require evaluation and testing to rule out COVID-19 in a designated area with the appropriate precautions. ${ }^{79}$ SOT recipients regularly undergo procedures. Aerosol generating procedures (AGP) (eg, intubation, bronchoscopy, gastrointestinal endoscopy, nasal and sinus endoscopy, swallowing evaluations, and administration of nebulized solutions) pose the greatest risk of SARS-CoV-2 transmission. In addition to symptom screening, many transplant hospitals have instituted routine testing prior to these procedures.

\subsection{1 | Preventing transmission from patients with suspected or confirmed COVID-19}

Patients with suspected or confirmed COVID-19 should be placed in a single-patient room with the door closed and a dedicated bathroom. Airborne infection isolation rooms (single-patient, negative-pressure room) should be reserved for patients who will undergo an AGP. To limit HCP exposure, facilities could designate a unit within their facility to care for patients with known or suspected COVID-19. With the same goal, HCP should be designated to work specifically in these units whenever possible. ${ }^{79} \mathrm{HCP}$ evaluating patients with suspected or confirmed COVID-19 should adhere to standard precautions and use a respirator (or a facemask if a respirator is not available), gown, gloves, and eye protection. If a patient with suspected or confirmed COVID-19 undergoes an AGP, the number of HCP in the room should be minimized and those present should wear a respirator.

\subsection{2 | When to discontinue isolation for persons with COVID-19}

In a study of 56 patients from Wuhan, China the median time between onset of symptoms to NP RT-PCR negative was 24 days. ${ }^{80}$ SARS-CoV-2 has not been cultured more than 9 days after the onset of symptoms in patients with mild disease; albeit the sample size of these studies was small. ${ }^{9,16}$ A larger study that included 129 patients, 89 (69\%) requiring intensive care and 30 (23\%) immunocompromised, described that infectious virus could be detected up to 20 days from upper respiratory specimens. ${ }^{81} \mathrm{~A}$ large contact tracing study demonstrated that highrisk household and hospital contacts did not develop infection if their exposure to a case patient started 6 days or more after the case patient's illness onset. ${ }^{82}$ The Korean CDC cultured 108 patients who retested positive at a median time of 44 days; all cultures were negative. The investigation also traced 790 contacts. Three new cases of COVID-19 were identified; all had other known exposures. ${ }^{83}$ Collectively, these data prompted an update to the CDC guidelines regarding the duration of isolation and precautions for adults with COVID-19 (Table 4). The revision favors a symptom-based strategy although a test-based strategy could be considered in consultation with infectious diseases experts for severely immunocompromised patients. ${ }^{84}$ Regardless of the strategy used retesting after discontinuation of isolation is discouraged.

There are little data to guide the decision to discontinue isolation in SOT recipients. There is concern, based on data with influenza, of prolonged infectivity with SARS-CoV-2 but this has not been confirmed. ${ }^{85}$ The optimal strategy (time or test based) and timing of discontinuation of isolation for SOT recipients with COVID-19 is unknown. A time-based strategy could increase the risk of transmissions. This risk can be minimized in the health care setting by a universal mask policy. A test-based strategy, in SOT, is limited by the availability of testing and lack of correlation between positive RT-PCR and infectivity. The duration of isolation proposed by the CDC for non-immunocompromised patients may also increase the risk of transmission if a longer duration of infectivity is ultimately confirmed. A longer duration of isolation could potentially delay required medical care. 
TAB LE 3 A potential guidance to phasing up transplant activity during the pandemic

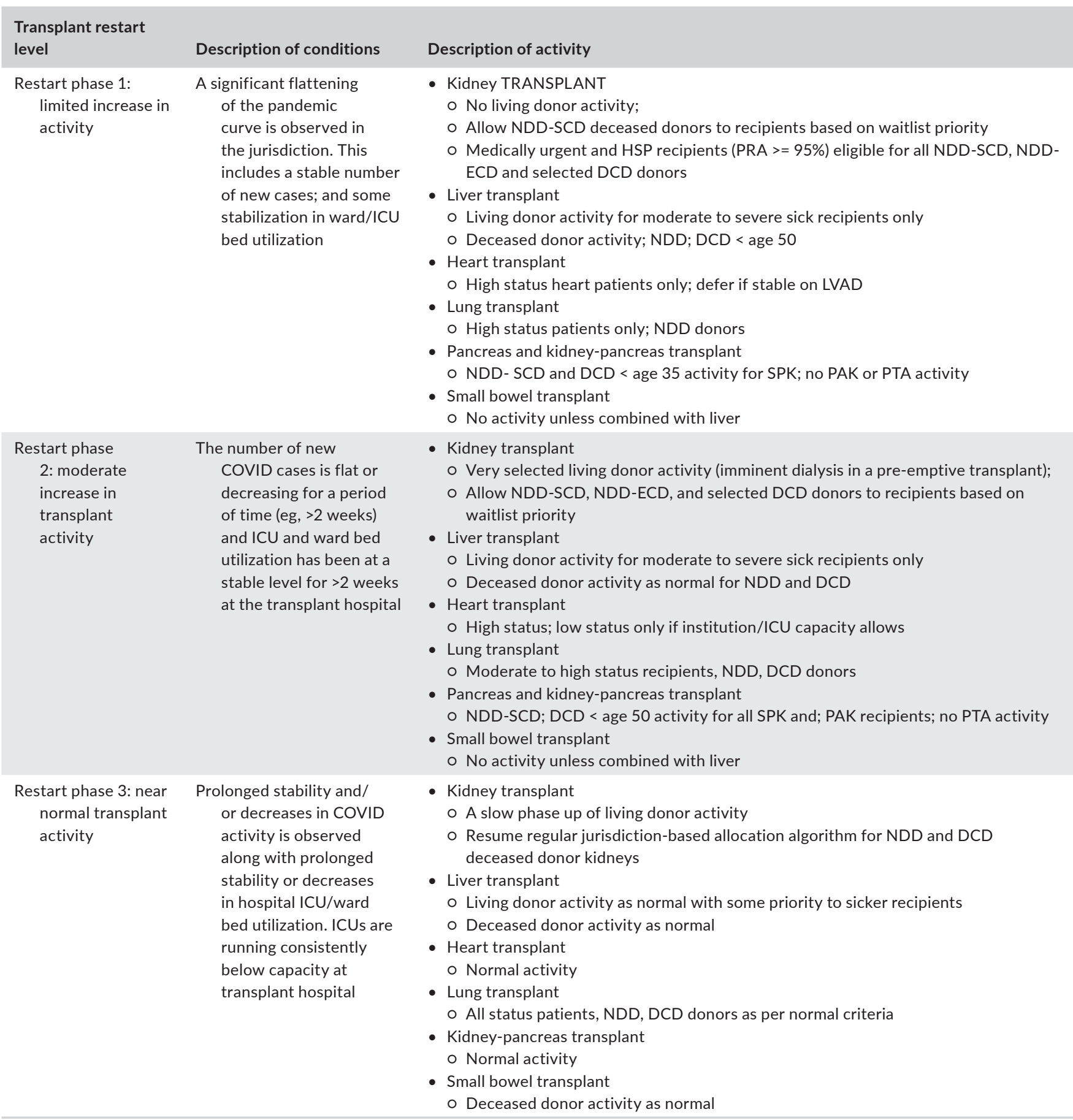

Abbreviations: NDD, neurological determination of death; $D C D$, donation after cardiocirculatory death; ECD, exceptional criteria donor; SCD, standard criteria donor; PRA, panel reactive antibody; SPK, simultaneous pancreas-kidney; PAK, pancreas after kidney; PTA, pancreas transplant alone; LVAD, left ventricular assist device.

a Modified from Trillium Gift of Life Network (TGLN) Ontario criteria for phased restart of transplant activity. The Table is provided only as a rough guidance to programs and should take into account other jurisdictional issues.

\subsection{3 | Measures to prevent transmission of SARS CoV-2 from HCP}

To minimize the spread of SARS-CoV-2 from one HCP to another, most centers have adopted the following measures. ${ }^{79} \mathrm{HCP}$ are asked to monitor themselves for symptoms compatible with COVID-19 and promptly contact infection control if symptomatic. All HCP are screened for COVID-19 compatible symptoms upon entering the health care facility. Despite these recommendations, a study from Washington, revealed that HCP worked for an average of 2 days 
TABLE 4 CDC - duration of isolation and precautions for adults with COVID-19

\section{Recommendations}

1. Duration of isolation and precautions

- For most persons with COVID-19 illness, isolation and precautions can generally be discontinued 10 days after symptom onset ${ }^{1}$ and resolution of fever for at least $24 \mathrm{~h}$, without the use of fever-reducing medications, and with improvement of other symptoms.

o. A limited number of persons with severe illness may produce replication-competent virus beyond 10 days that may warrant extending duration of isolation and precautions for up to 20 days after symptom onset; consider consultation with infection control experts.

- For persons who never develop symptoms, isolation and other precautions can be discontinued 10 days after the date of their first positive RT-PCR test for SARS-CoV-2 RNA.

2. Role of PCR testing to discontinue isolation or precautions

- For persons who are severely immunocompromised, a testbased strategy could be considered in consultation with infectious diseases experts.

- For all others, a test-based strategy is no longer recommended except to discontinue isolation or precautions earlier than would occur under the strategy outlined in Part 1, above.

3. Role of PCR testing after discontinuation of isolation or precautions

- For persons previously diagnosed with symptomatic COVID19 who remain asymptomatic after recovery, retesting is not recommended within 3 months after the date of symptom onset for the initial COVID-19 infection. In addition, quarantine is not recommended in the event of close contact with an infected person.

- For persons who develop new symptoms consistent with COVID-19 during the 3 months after the date of initial symptom onset, if an alternative etiology cannot be identified by a provider, then the person may warrant retesting; consultation with infectious disease or infection control experts is recommended. Isolation may be considered during this evaluation based on consultation with an infection control expert, especially in the event symptoms develop within 14 days after close contact with an infected person.

- For persons who never developed symptoms, the date of first positive RT-PCR test for SARS-CoV-2 RNA should be used in place of the date of symptom onset.

4. Role of serologic testing

- Serologic testing should not be used to establish the presence or absence of active SARS-CoV-2 infection or reinfection.

Note: Adapted from CDC Coronavirus Disease 2019 - Duration of Isolation and Precautions for Adults with COVID-19.

Abbreviations: COVID-19, coronavirus disease 2019; FDA, Food and Drug Administration; RNA, ribonucleic acid; RT-PCR, real-time polymerase chain reaction; SARS-CoV-2, severe acute respiratory syndrome coronavirus 2 .

${ }^{\mathrm{a}}$ These recommendations are not specific for immunosuppressed patients and it is unknown if it can be extrapolated to this population.

after the onset of symptoms. ${ }^{86}$ Furthermore, it noted that even expanded symptom-based screening fails to identify all infected HCP. For this reason, universal masking of HCP within the health care facility is strongly recommended.

\subsection{4 | Protecting the Organ Procurement Organization HCP}

The HCP of organ procurement organizations (OPOs) are also at risk of acquiring SARS-CoV-2. The first line of protection is the screening that is recommended for all patients before entering a health care facility. ${ }^{79}$ Regardless, the OPO team should review the donor electronic health record and independently perform clinical screening for epidemiological risk factors and symptoms compatible with COVID-19. In addition to SARS-CoV-2 donor testing, this information serves the dual purpose of protecting the OPO HCP and minimizing the risk of a SARS-CoV-2 donor-derived infection.

\section{7 | Pediatric-specific issues}

SARS-CoV-2 infection in the pediatric population has been associated with mild disease even in very young children. ${ }^{87}$ However, reports of clusters of unusual and sometimes severe conditions in children that begin to emerge 4-8 weeks after regions experience local outbreaks of SARS-CoV-2 have identified several potential post-infectious inflammatory syndromes, although not all cases have been associated with proven SARS-CoV-2 infection. The most concerning is the development of multisystem inflammatory syndrome that includes rash and shock, with symptoms overlapping with toxic shock syndrome and atypical Kawasaki disease. ${ }^{51,88,89}$ The CDC has proposed classifying these cases as Multisystem Inflammatory Syndrome in Children (MIS-C) associated with SARS-CoV-2. ${ }^{90}$ To date, MIS-C has not been reported in pediatric organ transplant recipients.

Data describing COVID-19 in pediatric SOT are limited. Initial reports from Italy described SARS-CoV-2 detection in 3 of 200 liver transplant recipients, none of whom developed clinical pulmonary disease and all had favorable outcomes. ${ }^{91}$ Another report described a 6-month-old infant with biliary atresia whose living donor (mother) tested positive for SARS-CoV-2 2 days after transplant. The infant also tested positive and developed transaminitis and patchy bilateral lung opacities on day 6 after transplant. A liver biopsy was interpreted as ACR, but the child did not respond to augmented immunosuppression and eventually improved with reduced immune suppression. This report raised concerns for possible donor-derived COVID-19 hepatitis although community acquisition would also be possible. ${ }^{92} \mathrm{~A} 3$ years old more than 2 years after orthotopic heart transplantation developed donor-specific anti-HLA antibodies after a recent viral illness. During therapy for AMR, the patient was coughing and tested positive for SARSCoV-2 by PCR from a nasal swab. No antiviral therapy or modification in immunosuppression aside from IVIG administration was provided. $^{93}$

Pediatric-specific COVID-19 treatment data are limited. Given the mild course in the vast majority of pediatric patients and the lack of current evidence that disease is more severe in pediatric transplant recipients, supportive care is the recommended 
treatment for COVID-19 in these patients. Remdesivir, ideally as part of clinical trial, has been proposed as the preferred agent if antiviral therapy is to be used, Two randomized trials enrolling down to the age of 12 years (NCT04292730, NCT04292899) ${ }^{94}$ and two expanded access protocols (NCT04302766 and NCT04323761) are currently available to children $<18$ years of age in the United States. ${ }^{94}$ Anecdotal use of COVID-19 convalescent plasma use in pediatric patients has been reported but further controlled data are needed to assess its efficacy and it is currently, available for children as an open clinical trial (ccpp19.org) or as a single-patient eIND ${ }^{43}$ for children considered at high risk of COVID-19 disease progression. There is no current evidence to support use of anti-cytokine/cytokine receptor antibodies in the treatment of COVID-19 in children.

\section{8 | Psychological and ethical considerations during the pandemic}

There is ample evidence that the COVID-19 pandemic has adversely impacted the psychological health of patients and providers alike. Harm-reduction strategies implemented to attenuate viral transmission-including physical distancing and quarantine-have increased social isolation, loneliness, anxiety, fear, depression, anger, cognitive changes, and posttraumatic stress symptoms. Business closures have further limited opportunities for social engagement and have contributed to severe financial and economic hardship for many families.

The psychological impact for transplant patients may be even more pronounced than that of the general public. Waitlisted patients and transplant recipients may still require some in-person clinic visits, laboratory visits, interventional procedures, and hospitalization during the pandemic, all of which may cause anxiety about potential viral exposure. The potentially higher mortality rate among transplant patients who are COVID+ also may trigger an escalation in anxiety and fear about possible exposure. For transplant candidates, many programs throughout the United States paused or restricted transplant surgeries, creating uncertainty among patients about increased waiting time for transplantation and associated morbidity and risk of mortality on the waiting list. The pandemic also may have altered the social circumstances for waitlisted patients, including changes in caregiving arrangements and increased isolation from traditional support systems. Planned posttransplant support mechanisms may also have been disrupted by physical distancing and travel restrictions. Those with preexisting mental health conditions or substance use disorders may be especially vulnerable to clinical levels of depression or anxiety and relapse to alcohol or drug use.

It is imperative that transplant programs have a process in place to assess the impact of COVID-19 on various domains of a patient's quality of life such as physical, psychological, and financial well-being. Repurposed use of tablets or other devices to enhance communication with patients who lack technology, as well as helping patients learn to effectively use the technology, may be necessary.
Nonurgent in-person clinic visits are restricted for many programs during the pandemic, which further distances the patients-and their caregivers-from the resources typically available to them. Periodic telephone or remote video visits with patients and caregivers by transplant social workers, psychologists, and psychiatrists are encouraged to assess the COVID-19 impact on the patient and his/her social support system. Use of specific tools to assess the COVID-specific impact on patients should be considered, including the Epidemic-Pandemic Impacts Inventory (EPII) and the COVID-19 Peritraumatic Distress Index (CPDI). Moreover, telehealth can be utilized to offer individual psychotherapy, virtual support groups for patients and/or caregivers, and connecting transplant patients and caregivers with peer mentors. Rapid and early response to COVID-related stress as well as clear communication from the transplant team about effective risk mitigation strategies may improve the long-term mental health outcomes for transplant patients.

Potential and former living donors also may experience heightened psychological stress in the COVID-19. Some family members and friends of transplant candidates whose living donation evaluation or surgery was postpone due to COVID-19 can be expected to have new ambivalence about donation due to changes in personal circumstances (eg, new caregiving responsibilities), financial stressors caused by the pandemic, anxiety about the risk of viral exposure in a hospital setting and the risk those around them at home, and new concerns about mortality if COVID+ and only one functioning kidney (eg, high rate of mortality among those with COVID and acute kidney injury). Transplant programs, including independent living donor advocates, must assess these new contextual considerations in their evaluation and follow-up contacts with potential and former living donors, respectively.

Finally, it is imperative that individual transplant providers and team dynamics be closely monitored during the COVID-19 pandemic. The impact of COVID-19 on their patients, necessary modifications in clinical practice, temporary pauses in transplant clinics and surgery, higher rates or mortality in transplant recipients with COVID-19, challenging ethical dilemmas in the face of scarce health care resources, and the personal impact of the pandemic on transplant providers make them vulnerable to both short- and long-term mental health sequelae. Ongoing, multi-component psychosocial resources and institutional support are needed.

\section{9 | Research priorities}

The pandemic creates unique challenges for the population of immunosuppressed transplant patients. These include ensuring equitable access for transplant candidates and recipients in relevant prospective clinical trials. Other questions that must be investigated including how to better manage immunosuppressive therapies. In theory, reducing immunosuppression can improve potential immunity against the virus; however, in the case of SARS-CoV-2 patients, 
a significant reduction of immunosuppression could hypothetically exacerbate inflammation and result in aberrant cytokine release. Some papers have been published, but their findings mostly reflect individual experiences all show different approaches in managing immunosuppression. ${ }^{1,3}$ Randomized trials that help answer this question are of paramount importance. The number of patients at each center are limited, thus domestic/international collaborations between centers are necessary. Other major questions that need further investigation are related to the role of commonly used immunosuppressive therapies in transplant patients such as steroids, calcineurin inhibitors, and antimetabolites in the disease process.

As of yet, there are no published studies beyond a case series describing the incidence and clinical course of SARS-Cov-2 in transplant recipients. Do transplant recipients who develop SARSCoV-2 have higher/more prolonged viral detection and infectivity? And do pediatric transplant patients serve as reservoirs for the community spread of SARS-CoV-2? Knowledge of the humoral and cell-mediated immune responses in transplant recipients to infection and future vaccines will also be important. Reactivation of other viruses during COVID infection, such as BK and CMV, require further investigation.

\section{DISCLOSURE}

The authors of this manuscript have no conflicts of interest to disclose as described by the American Journal of Transplantation.

\section{DATA AVAILABILITY STATEMENT}

There are no data to be shared.

\section{REFERENCES}

1. Pereira MR, Mohan S, Cohen DJ, et al. COVID-19 in solid organ transplant recipients: initial report from the US epicenter. Am J Transplant. 2020;20(7):1800-1808.

2. Nair V, Jandovitz N, Hirsch JS, et al. COVID-19 in kidney transplant recipients. Am J Transplant. 2020;20(7):1819-1825.

3. Akalin E, Azzi Y, Bartash R, et al. Covid-19 and kidney transplantation. N Engl J Med. 2020;382(25):2475-2477.

4. Hanson KE, Caliendo AM, Arias CA, et al. Infectious Diseases Society of America Guidelines on the Diagnosis of COVID-19. 2020. https://www.idsociety.org/practice-guideline/covid-19guideline-diagnostics/ Accessed September 18, 2020

5. Zou L, Ruan F, Huang M, et al. SARS-CoV-2 viral load in upper respiratory specimens of infected patients. $N$ Engl J Med. 2020;382(12):1177-1179.

6. He XI, Lau EHY, Wu P, et al. Temporal dynamics in viral shedding and transmissibility of COVID-19. Nat Med. 2020;26(5):672-675.

7. To K-W, Tsang O-Y, Yip C-Y, et al. Consistent detection of 2019 novel coronavirus in saliva. Clin Infect Dis. 2020;71(15):841-843.

8. Zheng S, Fan J, Yu F, et al. Viral load dynamics and disease severity in patients infected with SARS-CoV-2 in Zhejiang province, China, JanuaryMarch 2020: retrospective cohort study. BMJ. 2020;369:m1443.

9. Wölfel R, Corman VM, Guggemos W, et al. Virological assessment of hospitalized patients with COVID-2019. Nature. 2020;581(7809):465-469.

10. La Scola B, Le Bideau M, Andreani J, et al. Viral RNA load as determined by cell culture as a management tool for discharge of SARSCoV-2 patients from infectious disease wards. Eur J Clin Microbiol Infect Dis. 2020;39(6):1059-1061.
11. Wang W, Xu Y, Gao R, et al. Detection of SARS-CoV-2 in different types of clinical specimens. JAMA. 2020;323(18):1843-1844.

12. Siddiqi HK, Mehra MR. COVID-19 illness in native and immunosuppressed states: a clinical-therapeutic staging proposal. J Heart Lung Transplant. 2020;39(5):405-407.

13. Winichakoon P, Chaiwarith R, Liwsrisakun C, et al. Negative nasopharyngeal and oropharyngeal swabs do not rule out COVID-19. J Clin Microbiol. 2020;58(5):e00297-20.

14. Wang D, Hu B, Hu C, et al. Clinical characteristics of 138 hospitalized patients with 2019 novel coronavirus-infected pneumonia in Wuhan, China. JAMA. 2020;323(11):1061-1069.

15. Azzi L, Carcano G, Gianfagna F, et al. Saliva is a reliable tool to detect SARS-CoV-2. J Infect. 2020;81(1):e45-e50.

16. Arons MM, Hatfield KM, Reddy SC, et al. Presymptomatic SARSCoV-2 infections and transmission in a skilled nursing facility. N Engl J Med. 2020;382(22):2081-2090.

17. Kimball A, Hatfield KM, Arons $M$, et al. Asymptomatic and presymptomatic SARS-CoV-2 infections in residents of a long-term care skilled nursing facility - King County, Washington, March 2020. MMWR Morb Mortal Wkly Rep. 2020;69(13):377-381.

18. Moran A, Beavis KG, Matushek SM, et al. The detection of SARSCoV-2 using the Cepheid Xpert Xpress SARS-CoV-2 and Roche cobas SARS-CoV-2 assays. J Clin Microbiol. 2020;58(8):e00772-20.

19. Rhoads DD, Cherian SS, Roman K, Stempak LM, Schmotzer CL, Sadri N. Comparison of Abbott ID Now, Diasorin Simplexa, and CDC FDA EUA methods for the detection of SARS-CoV-2 from nasopharyngeal and nasal swabs from individuals diagnosed with COVID-19. J Clin Microbiol. 2020;58(8):e00760-20.

20. Zhen W, Manji R, Smith E, Berry GJ. Comparison of four molecular in vitro diagnostic assays for the detection of SARS-CoV-2 in nasopharyngeal specimens. J Clin Microbiol. 2020. https://doi. org/10.1128/jcm.00743-20

21. Zhen W, Smith E, Manji R, Schron D, Berry GJ. Clinical evaluation of three sample-to-answer platforms for the detection of SARSCoV-2. J Clin Microbiol. 2020;58(8):e00783-20.

22. Wong HYF, Lam HYS, Fong $\mathrm{AH}$, et al. Frequency and distribution of chest radiographic findings in COVID-19 positive patients. Radiology. 2020;296(2):E72-E78.

23. Fang Y, Zhang H, Xie J, et al. Sensitivity of chest CT for COVID-19: comparison to RT-PCR. Radiology. 2020;296(2):E115-E117.

24. Zhao J, Yuan Q, Wang $\mathrm{H}$, et al. Antibody responses to SARSCoV-2 in patients of novel coronavirus disease 2019. Clin Infect Dis. 2020:ciaa344. https://doi.org/10.1093/cid/ciaa344

25. Zhou F, Yu T, Du R, et al. Clinical course and risk factors for mortality of adult inpatients with COVID-19 in Wuhan, China: a retrospective cohort study. Lancet. 2020;395(10229):1054-1062.

26. Kates OS, Haydel BM, Florman SS, et al. COVID-19 in solid organ transplant: a multi-center cohort study. Clin Infect Dis. 2020; ciaa1097. https://doi.org/10.1093/cid/ciaa1097

27. Chaudhry ZS, Williams JD, Vahia A, et al. Clinical characteristics and outcomes of COVID-19 in solid organ transplant recipients: a case-control study. Am J Transplant. 2020. https://doi.org/10.1111/ ajt.16188

28. Dong L, Hu S, Gao J. Discovering drugs to treat coronavirus disease 2019 (COVID-19). Drug Discov Ther. 2020;14(1):58-60.

29. National Institutes of Health. COVID-19 Treatment Guidelines Panel. Coronavirus Disease 2019 (COVID-19) Treatment Guidelines. 2020.

30. WHO Scientific Brief. The use of non-steroidal anti-inflammatory drugs (NSAIDs) in patients with COVID-19. 2020.

31. Vaduganathan M, Vardeny O, Michel T, McMurray JJV, Pfeffer MA, Solomon SD. Renin-angiotensin-aldosterone system inhibitors in patients with Covid-19. N Engl J Med. 2020;382(17):1653-1659.

32. WHO Scientific Brief. COVID-19 and the use of angiotensin-converting enzyme inhibitors and receptor blockers. 2020. 
33. RECOVERY Collaborative Group, Horby P, Lim WS, et al. Dexamethasone in hospitalized patients with Covid-19 - preliminary report. N Engl J Med. 2020;NEJMoa2021436. https://doi. org/10.1056/NEJMoa2021436

34. WHO Rapid Evidence Appraisal for COVID-19 Therapies (REACT) Working Group, Sterne JAC, Murthy S, et al. Association between administration of systemic corticosteroids and mortality among critically ill patients with COVID-19: a meta-analysis. JAMA. 2020;324(13):1-13.

35. NIH halts clinical trial of hydroxychloroquine. Media advisory. 2020. https://www.nih.gov/news-events/news-releases/nih-halts -clinical-trial-hydroxychloroquine. Accessed September 18, 2020

36. Geleris J, Sun Y, Platt J, et al. Observational study of hydroxychloroquine in hospitalized patients with Covid-19. N Engl J Med. 2020;382(25):2411-2418.

37. Tang $\mathrm{W}, \mathrm{Cao} Z$, Han M, et al. Hydroxychloroquine in patients with mainly mild to moderate coronavirus disease 2019: open label, randomised controlled trial. BMJ. 2020;369:m1849.

38. Cao B, Wang Y, Wen D, et al. A trial of lopinavir-ritonavir in adults hospitalized with severe Covid-19. N Engl J Med. 2020;382(19):1787-1799.

39. Beigel JH, Tomashek KM, Dodd LE, et al. Remdesivir for the treatment of Covid-19 - preliminary report. N Engl J Med. 2020:NEJMoa2007764. https://doi.org/10.1056/NEJMoa2007764

40. Grein J, Ohmagari N, Shin D, et al. Compassionate use of remdesivir for patients with severe Covid-19. N Engl J Med. 2020;382(24):2327-2336.

41. Goldman JD, Lye DCB, Hui DS, et al. Remdesivir for 5 or 10 days in patients with severe Covid-19. N Engl J Med. 2020;NEJMoa2015301. https://doi.org/10.1056/NEJMoa2015301

42. US Food and Drug Administration. Remdesivir letter of EUA. 2020. https://www.fda.gov/news-events/press-announcements/ coronavirus-covid-19-update-fda-issues-emergency-use-autho rization-potential-covid-19-treatment Accessed September 18, 2020.

43. US Food and Drug Administration. Recommendations for investigational COVID-19 convalescent plasma. 2020. https://www.fda.gov/ vaccines-blood-biologics/investigational-new-drug-ind-or-deviceexemption-ide-process-cber/recommendations-investigational-covid -19-convalescent-plasma Accessed September 18, 2020.

44. Yang $X, Y u Y, X u$ J, et al. Clinical course and outcomes of critically ill patients with SARS-CoV-2 pneumonia in Wuhan, China: a single-centered, retrospective, observational study. Lancet Respir Med. 2020;8(5):475-481.

45. Somers EC, Eschenauer GA, Troost JP, et al. Tocilizumab for treatment of mechanically ventilated patients with COVID-19. Clin Infect Dis. 2020;ciaa954. https://doi.org/10.1093/cid/ciaa954

46. Guaraldi G, Meschiari M, Cozzi-Lepri A, et al. Tocilizumab in patients with severe COVID-19: a retrospective cohort study. Lancet Rheumatol. 2020;2(8):e474-e484.

47. Rodriguez-Bano J, Pachon J, Carratala J, et al. Treatment with tocilizumab or corticosteroids for COVID-19 patients with hyperinflammatory state: a multicentre cohort study (SAM-COVID-19). Clin Microbiol Infect. 2020. https://doi.org/10.1016/j.cmi.2020. 08.010

48. Perez-Saez MJ, Blasco M, Redondo-Pachon D, et al. Use of tocilizumab in kidney transplant recipients with COVID-19. Am J Transplant. 2020. https://doi.org/10.1111/ajt.16192

49. Roche provides an update on the phase III COVACTA trial of Actemra/RActemra in hospitalised patients with severe COVID-19 associated pneumonia. 2020. Press release. https://www.roche. com/investors/updates/inv-update-2020-07-29.html Accessed September 18, 2020.

50. Sanofi and Regeneron provide update on Kevzara (sarilumab) Phase 3 U.S. trial in COVID-19 patients. Press release. 2020.
51. Mehta P, McAuley DF, Brown M, et al. COVID-19: consider cytokine storm syndromes and immunosuppression. Lancet. 2020;395(10229):1033-1034.

52. Clinical best practice advice for hepatology and liver transplant providers during the COVID-19 pandemic: AASLD expert panel consensus statement. 2020.

53. Sung AD, Sung JAM, Thomas $S$, et al. Universal mask usage for reduction of respiratory viral infections after stem cell transplant: a prospective trial. Clin Infect Dis. 2016;63(8):999-1006.

54. Agena F, Prado EDS, Souza PS, et al. Home blood pressure (BP) monitoring in kidney transplant recipients is more adequate to monitor BP than office BP. Nephrol Dial Transplant. 2011;26(11):3745-3749.

55. Omboni S. Connected health in hypertension management. Front Cardiovasc Med. 2019;6:76

56. Duan Y, Xie Z, Dong F, et al. Effectiveness of home blood pressure telemonitoring: a systematic review and meta-analysis of randomised controlled studies. J Hum Hypertens. 2017;31(7): 427-437.

57. Brennan DC, Daller JA, Lake KD, Cibrik D, Del Castillo D; Thymoglobulin Induction Study Group. Rabbit antithymocyte globulin versus basiliximab in renal transplantation. N Engl J Med. 2006;355(19):1967-1977.

58. Thomusch O, Wiesener M, Opgenoorth M, et al. Rabbit-ATG or basiliximab induction for rapid steroid withdrawal after renal transplantation (Harmony): an open-label, multicentre, randomised controlled trial. Lancet. 2016;388(10063):3006-3016.

59. Kamar N, Esposito L, Hebral AL, Guitard J, Del Bello A. Specific organization for in-hospital belatacept infusion to avoid nosocomial transmission during the SARS-CoV-2 pandemic. Am J Transplant. 2020;20(10):2962-2963.

60. Chang L, Zhao L, Gong H, Wang L, Wang L. Severe acute respiratory syndrome coronavirus 2 RNA detected in blood donations. Emerg Infect Dis. 2020;26(7):1631-1633.

61. Danziger-Isakov L, Kumar D; AST ID Community of Practice. Vaccination of solid organ transplant candidates and recipients: guidelines from the American society of transplantation infectious diseases community of practice. Clin Transplant. 2019;33(9):e13563.

62. Kumar D, Manuel O, Natori Y, et al. COVID-19: a global transplant perspective on successfully navigating a pandemic. Am J Transplant. 2020;20(7):1773-1779.

63. Gruttadauria S; Italian Board of Experts in Liver Transplantation (I-BELT) Study Group, The Italian Society of Organ Transplantation (SITO). Preliminary analysis of the Impact of the coronavirus disease 2019 outbreak on Italian liver transplant programs. Liver Transpl. 2020;26(7):941-944.

64. Kates OS, Fisher CE, Rakita RM, Reyes JD, Limaye AP. Use of SARSCoV-2-infected deceased organ donors: should we always "just say no?". Am J Transplant. 2020;20(7):1787-1794.

65. Amirian ES. Potential fecal transmission of SARS-CoV-2: current evidence and implications for public health. Int J Infect Dis. 2020;95:363-370.

66. Tavazzi G, Pellegrini C, Maurelli M, et al. Myocardial localization of coronavirus in COVID-19 cardiogenic shock. Eur J Heart Fail. 2020;22(5):911-915

67. Su H, Yang M, Wan C, et al. Renal histopathological analysis of 26 postmortem findings of patients with COVID-19 in China. Kidney Int. 2020;98(1):219-227.

68. Shah MB, Lynch RJ, El-Haddad H, Doby B, Brockmeier D, Goldberg DS. Utilization of deceased donors during a pandemic: argument against using SARS-CoV-2-positive donors. Am J Transplant. 2020;20(7):1795-1799.

69. American Society of Transplantation. 2019-nCoV (Coronavirus): Recommendations and Guidance for Organ Donor Testing. https:// www.myast.org/covid-19-information. July 8, 2020. Accessed September 18, 2020 
70. Liu R, Han H, Liu F, et al. Positive rate of RT-PCR detection of SARSCoV-2 infection in 4880 cases from one hospital in Wuhan, China, from Jan to Feb 2020. Clin Chim Acta. 2020;505:172-175.

71. Lopez Roa P, Rodriguez-Sanchez B, Catalan P, et al. Diagnosis of influenza in intensive care units: lower respiratory tract samples are better than nose-throat swabs. Am J Respir Crit Care Med. 2012;186(9):929-930.

72. Pan Y, Long L, Zhang D, et al. Potential false-negative nucleic acid testing results for severe acute respiratory syndrome coronavirus 2 from thermal inactivation of samples with low viral loads. Clin Chem. 2020;66(6):794-801.

73. Loupy A, Aubert O, Reese PP, Bastien O, Bayer F, Jacquelinet C. Organ procurement and transplantation during the COVID-19 pandemic. Lancet. 2020;395(10237):e95-e96.

74. Boyarsky BJ, Po-Yu Chiang T, Werbel WA, et al. Early impact of COVID-19 on transplant center practices and policies in the United States. Am J Transplant. 2020;20(7):1809-1818.

75. CDC Covid- Response Team. Characteristics of health care personnel with COVID-19 - United States, February 12-April 9, 2020. MMWR Morb Mortal Wkly Rep. 2020;69(15):477-481.

76. Wu Z, McGoogan JM. Characteristics of and important lessons from the coronavirus disease 2019 (COVID-19) outbreak in china: summary of a report of 72314 cases from the Chinese Center for Disease Control and Prevention. JAMA. 2020;323(13):1239-1242.

77. Instituto Superiore di Sanità. Integrated surveillance COVID-19: the main national data. 2020. https://www.epicentro.iss.it/coronaviru s/sars-cov-2-sorveglianza-dati. Accessed September 18, 2020.

78. Agnes S, Andorno E, Avolio AW, et al. Preliminary analysis of the impact of COVID-19 outbreak on Italian liver transplant programs. Liver Transpl. 2020. https://doi.org/10.1002/It.25790

79. Center for Disease Control and Prevention. Interim infection prevention and control recommendations for patients with suspected or confirmed coronavirus disease 2019 (COVID-19) in healthcare settings. 2020. https://www.cdc.gov/coronavirus/2019-ncov/ hcp/infection-control-recommendations.html. Accessed May 20, 2020

80. Xiao AT, Tong YX, Zhang S. Profile of RT-PCR for SARS-CoV-2: a preliminary study from 56 COVID-19 patients. Clin Infect Dis. 2020;ciaa460. https://doi.org/10.1093/cid/ciaa460

81. van Kampen JJA, van de Vijver DAMC, Fraaij PLA, et al. Shedding of infectious virus in hospitalized patients with coronavirus disease-2019 (COVID-19): duration and key determinants. medRxiv. https://doi.org/10.1101/2020.06.08.20125310

82. Cheng HY, Jian SW, Liu DP, et al. Contact tracing assessment of COVID-19 transmission dynamics in Taiwan and risk at different exposure periods before and after symptom onset. JAMA Intern Med. 2020;180(9):1156-1163.

83. Korean Center for Disease Control and Prevention. Findings from investigation and analysis of re-positive cases. 2020. https://www.cdc.go.kr/board/board.es?mid=a304020000 00\&bid=0030\&act=view\&list_no $=367267 \& n P a g e=1$. Accessed May 20, 2020

84. Centers for Disease Control and Prevention. Discontinuation of Transmission-Based Precautions and Disposition of Patients with COVID-19 in Healthcare Settings (Interim Guidance). 2020. https:// www.cdc.gov/coronavirus/2019-ncov/hcp/disposition-hospitaliz ed-patients.html Accessed July 17, 2020.

85. Manuel O, Estabrook M; American Society of Transplantation Infectious Diseases Community of Practice. RNA respiratory viral infections in solid organ transplant recipients: Guidelines from the American Society of Transplantation Infectious Diseases Community of Practice. Clin Transplant. 2019;33(9):e13511.

86. Chow EJ, Schwartz NG, Tobolowsky FA, et al. Symptom screening at illness onset of health care personnel with SARS-CoV-2 infection in King County, Washington. JAMA. 2020;323(20):2087-2089.
87. Liguoro I, Pilotto C, Bonanni M, et al. SARS-COV-2 infection in children and newborns: a systematic review. Eur J Pediatr. 2020;179(7):1029-1046.

88. Jones VG, Mills M, Suarez D, et al. COVID-19 and kawasaki disease: novel virus and novel case. Hosp Pediatr. 2020;10(6):537-540.

89. Esper F, Shapiro ED, Weibel C, Ferguson D, Landry ML, Kahn JS. Association between a novel human coronavirus and Kawasaki disease. J Infect Dis. 2005;191(4):499-502.

90. Centers for Disease Control and Prevention. Multisystem Inflammatory Syndrome in Children (MIS-C) Associated with Coronavirus Disease 2019 (COVID-19) May 14, 2020.

91. D'Antiga L. Coronaviruses and immunosuppressed patients: the facts during the third epidemic. Liver Transpl. 2020;26(6):832-834.

92. Lagana SM, De Michele S, Lee MJ, et al. COVID-19 associated hepatitis complicating recent living donor liver transplantation. Arch Pathol Lab Med. 2020. https://doi.org/10.5858/ arpa.2020-0186-SA

93. Russell MR, Halnon NJ, Alejos JC, Salem MM, Reardon LC. COVID19 in a pediatric heart transplant recipient: emergence of donor-specific antibodies. J Heart Lung Transplant. 2020;39(7):732-733.

94. Chiotos K, Hayes M, Kimberlin DW, et al. Multicenter initial guidance on use of antivirals for children with COVID-19/SARS-CoV-2. J Pediatric Infect Dis Soc. 2020:piaa045. https://doi.org/10.1093/ jpids/piaa045

95. Valk SJ, Piechotta V, Chai KL, et al. Convalescent plasma or hyperimmune immunoglobulin for people with COVID-19: a rapid review. Cochrane Database Syst Rev. 2020;5:CD013600.

How to cite this article: . C4 article: Implications of COVID-19 in transplantation. Am J Transplant. 2020;00:1-15. https://doi.org/10.1111/ajt.16346

\section{APPENDIX 1}

\section{Editors and contributors}

\begin{tabular}{|c|c|}
\hline Justin G. Aaron & $\begin{array}{l}\text { Division of Infectious Diseases, Columbia } \\
\text { University College of Physicians \& } \\
\text { Surgeons, New York, New York }\end{array}$ \\
\hline Lilian M. Abbo & $\begin{array}{l}\text { University of Miami, Miami Transplant } \\
\text { Institute and Jackson Health System, } \\
\text { Miami, Florida }\end{array}$ \\
\hline Felipe Alconchel & $\begin{array}{l}\text { Department of Surgery and Organ } \\
\text { Transplantation. Virgen de la Arrixaca } \\
\text { University Hospital (IMIB-Arrixaca), } \\
\text { Murcia, Spain }\end{array}$ \\
\hline Cristiano Amarelli & Monaldi, Azienda dei Colli, Naples, Italy \\
\hline Shweta Anjan & $\begin{array}{l}\text { University of Miami Miller School of } \\
\text { Medicine, Miami, Florida }\end{array}$ \\
\hline Monica I. Ardura & $\begin{array}{l}\text { Nationwide Children's Hospital \& The Ohio } \\
\text { State University, Columbus, Ohio }\end{array}$ \\
\hline Marwan M. Azar & Yale University, New Haven, Connecticut \\
\hline Jamil Azzi* & $\begin{array}{c}\text { Renal Division, Brigham and Women's } \\
\text { Hospital, Boston, Massachusetts }\end{array}$ \\
\hline John W. Baddley & $\begin{array}{l}\text { University of Maryland School of Medicine, } \\
\text { Baltimore, Maryland }\end{array}$ \\
\hline Wendy Balliet & $\begin{array}{l}\text { Medical University of South Carolina, } \\
\text { Charleston, South Carolina }\end{array}$ \\
\hline
\end{tabular}


APPENDIX 1 (Continued)

\begin{tabular}{|c|c|}
\hline Maria Irene Bellini & $\begin{array}{l}\text { Belfast Health and Social Care Trust, Belfast, } \\
\text { Northern Ireland }\end{array}$ \\
\hline Emily Blumberg* & $\begin{array}{l}\text { Division of Infectious Diseases, Perelman } \\
\text { School of Medicine, University of } \\
\text { Pennsylvania, Philadelphia, Pennsylvania }\end{array}$ \\
\hline James A. Blumenthal & $\begin{array}{l}\text { Duke University Medical Center, Durham, } \\
\text { North Carolina }\end{array}$ \\
\hline $\begin{array}{l}\text { Heather } M . \\
\text { Bruschwein }\end{array}$ & $\begin{array}{l}\text { University of Virginia School of Medicine, } \\
\text { Charlottesville, Virginia }\end{array}$ \\
\hline Lara Danziger-Isakov & $\begin{array}{l}\text { Cincinnati Children's Hospital Medical Center, } \\
\text { Cincinnati, Ohio }\end{array}$ \\
\hline Valerie Demekhin & $\begin{array}{l}\text { North Shore University Hospital, Manhasset, } \\
\quad \text { New York }\end{array}$ \\
\hline Daniel E. Dulek & $\begin{array}{l}\text { Vanderbilt University Medical Center, } \\
\text { Nashville, Tennessee }\end{array}$ \\
\hline $\begin{array}{l}\text { Gustavo Fernandes } \\
\text { Ferreira }\end{array}$ & $\begin{array}{l}\text { Transplant Center Santa Casa de Juiz de Fora, } \\
\text { Juiz de Fora, Brazil }\end{array}$ \\
\hline Alessandro Gambella & $\begin{array}{l}\text { Pathology Unit, Department of Medical } \\
\text { Sciences, University of Turin, Turin, Italy }\end{array}$ \\
\hline Emmanouil Giorgakis & UAMS Medical Center, Little Rock, Arkansas \\
\hline Melissa R. Gitman & $\begin{array}{l}\text { Icahn School of Medicine at Mount Sinai, } \\
\text { New York, New York }\end{array}$ \\
\hline Kristina L. Goff & $\begin{array}{l}\text { UT Southwestern Medical Center, Dallas, } \\
\text { Texas }\end{array}$ \\
\hline Michael Green* & $\begin{array}{l}\text { Division of Infectious Diseases, UPMC } \\
\text { Children's Hospital of Pittsburgh, } \\
\text { Department of Pediatrics and Surgery, } \\
\text { University of Pittsburgh School of } \\
\text { Medicine, Pittsburgh, Pennsylvania }\end{array}$ \\
\hline Melissa A. Greenwald & Donor Alliance, Denver, Colorado \\
\hline Jonathan Hand & Ochsner Health, New Orleans, Louisiana \\
\hline $\begin{array}{l}\text { Marion } \\
\text { Hemmersbach- } \\
\text { Miller }\end{array}$ & Baylor College of Medicine, Dallas, Texas \\
\hline Atul Humar* & $\begin{array}{l}\text { Transplant Centre, University Health } \\
\text { Network, Toronto, Canada }\end{array}$ \\
\hline Michael G. Ison* & $\begin{array}{l}\text { Divisions of Infectious Diseases and Organ } \\
\text { Transplantation, Northwestern University } \\
\text { Feinberg School of Medicine, Chicago, } \\
\text { Illinois }\end{array}$ \\
\hline Andrés Jaramillo & Mayo Clinic, Phoenix, Arizona \\
\hline Michelle T. Jesse & Henry Ford Health System, Detroit, Michigan \\
\hline $\begin{array}{l}\text { Camille Nelson } \\
\text { Kotton* }\end{array}$ & $\begin{array}{l}\text { Massachusetts General Hospital, Boston, } \\
\text { Massachusetts }\end{array}$ \\
\hline Kristin Kronsnoble & Tampa General Hospital, Tampa, Florida \\
\hline Deepali Kumar* & University Health Network, Toronto, Canada \\
\hline Ricardo M. La Hoz* & $\begin{array}{l}\text { University of Texas Southwestern Medical } \\
\text { Center, Dallas, Texas }\end{array}$ \\
\hline Krista Lentine & Saint Louis University, St. Louis, Missouri \\
\hline Santiago M.C. Lopez & $\begin{array}{l}\text { Sanford Children's Hospital; University of } \\
\text { South Dakota, Sanford Research. Sioux } \\
\text { Falls, South Dakota }\end{array}$ \\
\hline
\end{tabular}

APPENDIX 1 (Continued)

\begin{tabular}{|c|c|}
\hline Benjamin A. Miko & $\begin{array}{l}\text { Columbia University Medical Center, New } \\
\text { York, New York }\end{array}$ \\
\hline Sumit Mohan & $\begin{array}{l}\text { Division of Nephrology, Department of } \\
\text { Medicine, Vagelos College of Physicians } \\
\text { \& Surgeons and Department of } \\
\text { Epidemiology, Mailman School of Public } \\
\text { Health, Columbia University, New York, } \\
\text { New York }\end{array}$ \\
\hline Naoka Murakami & $\begin{array}{l}\text { Brigham and Women's Hospital, Boston, } \\
\text { Massachusetts }\end{array}$ \\
\hline Patti Niles & Southwest Transplant Alliance, Dallas, Texas \\
\hline Annelise Nolan & $\begin{array}{l}\text { Medstar Georgetown University Hospital, } \\
\text { Washington, DC }\end{array}$ \\
\hline Camilla W. Nonterah & University of Richmond, Richmond, Virginia \\
\hline Jeong M. Park & University of Michigan, Ann Arbor, Michigan \\
\hline $\begin{array}{l}\text { Rebecca Pellett } \\
\text { Madan }\end{array}$ & $\begin{array}{l}\text { NYU Langone School of Medicine, New York, } \\
\text { New York }\end{array}$ \\
\hline Marcus R. Pereira & $\begin{array}{l}\text { Columbia University Irving Medical Center, } \\
\text { New York, New York }\end{array}$ \\
\hline $\begin{array}{l}\text { Armelle Perez Cortes } \\
\quad \text { Villalobos }\end{array}$ & $\begin{array}{l}\text { UHN Toronto General Hospital, Toronto, } \\
\text { Canada }\end{array}$ \\
\hline Nicole Pilch & MUSC, Charleston, South Carolina \\
\hline Lisa M. Potter* & $\begin{array}{c}\text { Department of Pharmacy, University of } \\
\text { Chicago Medicine, Chicago, Illinois }\end{array}$ \\
\hline James R. Rodrigue* & $\begin{array}{l}\text { The Transplant Institute, Beth Israel } \\
\text { Deaconess Medical Center, Boston, } \\
\text { Massachusetts }\end{array}$ \\
\hline $\begin{array}{l}\text { Mia Schmiedeskamp- } \\
\text { Rahe }\end{array}$ & $\begin{array}{l}\text { University of Illinois at Chicago College of } \\
\text { Pharmacy, Chicago, Illinois }\end{array}$ \\
\hline Dhruva Sharma & $\begin{array}{l}\text { Department of Cardiothoracic and Vascular } \\
\text { Surgery, S.M.S. Medical College, Jaipur, } \\
\text { India }\end{array}$ \\
\hline Amany Sholkamy & Cairo University, Cairo, Egypt \\
\hline Neeraj Singh & $\begin{array}{l}\text { Willis Knighton Health System, Shreveport, } \\
\text { Louisiana }\end{array}$ \\
\hline Ekamol Tantisattamo & $\begin{array}{l}\text { University of California Irvine School of } \\
\text { Medicine, Irvine, California }\end{array}$ \\
\hline Yasemin Tezer & $\begin{array}{l}\text { Turkey Health Ministry Bilkent City Hospital, } \\
\text { Ankara, Turkey }\end{array}$ \\
\hline $\begin{array}{l}\text { Nicole M. } \\
\text { Theodoropoulos* }\end{array}$ & $\begin{array}{l}\text { Division of Infectious Diseases and } \\
\text { Immunology, University of Massachusetts } \\
\text { Medical School, Worcester, } \\
\text { Massachusetts }\end{array}$ \\
\hline Crystal Truax & $\begin{array}{l}\text { University of Utah Health, Salt Lake City, } \\
\text { Utah }\end{array}$ \\
\hline Benito Valdepenas & $\begin{array}{l}\text { University of Illinois at Chicago College of } \\
\text { Pharmacy, Chicago, Illinois }\end{array}$ \\
\hline Deborah Verran & $\begin{array}{l}\text { Ramsay HealthCare Australia, Macquarie } \\
\text { Park, Australia }\end{array}$ \\
\hline Scott G. Westphal & $\begin{array}{l}\text { University of Nebraska Medical Center, } \\
\text { Lincoln, Nebraska }\end{array}$ \\
\hline
\end{tabular}

* Indicates contributor was an editor for the C4 Article. 